\title{
Morfin i behandlingen av akutt lungeødem
}

\begin{abstract}
BAKGRUNN I Norge og i resten av Europa er morfin fremdeles en del av behandlingen ved lungeødem. Det vitenskapelige grunnlaget for dette er tynt. I denne artikkelen vurderer vi litteraturen som støtter slik bruk og litteratur der man er kritisk til bruk av morfin ved lungeødem.
\end{abstract}

KUNNSKAPSGRUNNLAG Artikkelen er basert på et litteratursøk i Medline og Embase og på artikkelgrunnlaget i norske og internasjonale retningslinjer.

RESULTATER Morfin har i flere tiår vært brukt ved lungeødem grunnet preparatets anxiolytiske og vasodilaterende egenskaper. Det er beskrevet at morfin gir vasodilatasjon hos andre pasientgrupper, men det er få holdepunkter i litteraturen for at morfin gir vasodilatasjon hos pasienter med lungeødem. Trolig er det den uspesifikke depresjonen av sentralnervesystemet som har størst betydning for den endrede hemodynamikken ved lungeødem. Retrospektive studier har vist dels negativ, dels nøytral effekt ved akutt dekompensert hjertesvikt. Det foreligger ingen pålitelige kliniske studier som dokumenterer at morfin gir bedre prognose.

FORTOLKNING Basert på studiene som foreligger kan man ikke utelukke at bruk av morfin gir økt dødelighet ved akutt lungeødem. I tillegg er det få holdepunkter for at morfinets vasodilaterende egenskaper har betydning ved tilstanden. Nytten og risikoen ved bruk av morfin ved akutt lungeødem er fortsatt uavklart, men det er foreløpig lite som taler for at nytten av preparatet er god.

Pasienter med akutt lungeødem er noe leger jevnlig møter i akuttmedisinsk praksis. Mange ulike tilstander kan direkte og indirekte føre til dette. I denne artikkelen omtaler vi lungeødem av kardial årsak. De vanligste årsakene er arytmi, alvorlig hypertensjon, klaffefeil og strukturell skade av venstre ventrikkel, for eksempel etter hjerteinfarkt. Det er beskrevet en betydelig dødelighet ved denne diagnosen $(1,2)$.

Ødemet oppstår når venstre ventrikkel svikter, slik at det hydrostatiske trykket i lungekretsløpet øker og væske presses ut i lungenes interstitium og alveoler. Tilstanden er definert ved alvorlig pustebesvær som forverres i liggende stilling, knatrelyder over lungene og tegn på uttalt lungestuvning på røntgen thorax (3). Perifer oksygenmetning er vanligvis under $90 \%$ før behandlingen starter.

Den medikamentelle behandlingen av lungeødem er rettet mot det økte hydrostatiske trykket i lungekretsløpet, først og fremst ved å senke fyllingstrykket (preload), deretter ved å senke det perifere arterietrykket (afterload) - oppnådd gjennom venøs og arteriell kardilatasjon (4). Tradisjonelt har det også vært lagt vekt på å fjerne overflødig væske gjennom økt diurese (5).

Ved siden av oksygenbehandling er det siden 1960-årene tre medikamenter som har vært mest brukt for å oppnå disse effektene. Det er furosemid, som ved å hemme reopptaket av natrium i Henles sløyfe og distale tubuli øker utskillingen av væske gjennom nyrene. Så er det nitroglyserin, som via cGMP og relaksasjon av glatt muskulatur gir vaso- dilatasjon - i lave doser kun venøs, i høye doser også arteriell $(6,7)$. Dette reduserer fyllingstrykket for høyre ventrikkel i tillegg til arterietrykket for venstre ventrikkel. Det tredje medikamentet, morfin, er tema i denne artikkelen. Av disse tre medikamentene er det nitroglyserin som har størst og raskest effekt på reduksjon av fyllingstrykket (4).

Morfin har vært brukt som vasodilatator og anxiolytikum. Etter hvert er det blitt en diskusjon omkring nytten og ikke minst risikoen knyttet til denne bruken ved lungeødem $(1,4,8-11)$. I en retrospektiv studie fra 2008, basert på ADHERE-registeret, fant man at morfin gitt ved akutt dekompensert hjertesvikt var en uavhengig faktor for økt sykehusdødelighet, med en oddsratio på 4,8 $(95 \% \mathrm{KI}: 4,52-5,18, \mathrm{p}<0,001)(2)$. fremdeles ofte en del av behandlingen ved akutt lungeødem (12-14). Vi ønsker i denne artikkelen å sammenfatte den tilgjengelige litteraturen omkring bruken av morfin i behandlingen av lungeødem.

\section{Kunnskapsgrunnlag}

Vi har gjort litteratursøk i Medline med søkeordene «pulmonary edema» OR «lung edema» OR «acute heart failure» AND «morphine». Søket ble utført i februar 2014 og ga 263 treff. Tilsvarende søk ble gjort i Embase, der Medline-artikler ble ekskludert og søket begrenset til engelskspråklige artikler (191 treff).

Vi var særlig interessert i studier som dokumenterer utfallet ved bruk av morfin
I Norge og Europa for øvrig er morfin

\author{
Christoffer Ellingsrud \\ cellingsrud@gmail.com \\ Det medisinske fakultet \\ Universitetet i Oslo \\ Stefan Agewall \\ Hjerteklinikken \\ Oslo universitetssykehus, Ullevål
}

Manuskriptet er basert på førsteforfatters obligatoriske oppgave ved Det medisinske fakultet. Universitetet i Oslo.

Se også kunnskapsprøve på www.tidsskriftet.no/quiz

HOVEDBUDSKAP

Morfin har lenge vært brukt i behandlingen av akutt lungeødem

Det finnes ingen dokumentasjon for at morfin gir bedre prognose.

Studier har antydet at bruk av morfin gir $ø k t$ dødelighet

Pålitelige kliniske forsøk må avklare morfinets rolle ved lungeødem 
samt originalartikler og oversiktsartikler der effektene av medikamentet omtales. Totalt 25 artikler ble skjønnsmessig plukket ut etter gjennomgang av titler og sammendrag (2, $4-11,15-30)$. De øvrige artiklene som danner grunnlaget for denne artikkelen, er amerikanske, europeiske og norske retningslinjer $(12-14,31,32)$ samt artikler funnet etter søk i referanselister og etter innspill fra fagvurderere.

\section{Retningslinjer}

De europeiske retningslinjene (fra European Society of Cardiology, ESC) fra 2012 sier at man kan vurdere å gi 4-8 mg morfin intravenøst (gjentatt ved behov) dersom pasienten har alvorlig angst eller uro ved lungeødem (fig 1) (12).

Heart Failure Society of America har ikke med morfin i sine anbefalinger fra 2010 og skriver at medikamentet bør brukes med forsiktighet dersom det gis (31). Det kardiologiske samarbeidet American College of Cardiology Foundation/American Heart Association nevner ikke morfin i sine retningslinjer fra 2013 (32).

\section{Fysiologiske effekter av morfin}

Morfin gir en depresjon av sentralnervesystemet via opiatreseptorer i hjernen. Dette gir både sedasjon og analgesi (15). I tillegg har morfin en angstdempende effekt, som sammen med sedasjonen gir redusert aktivitet i det sympatiske nervesystemet og fører til en reduksjon av både fyllingstrykket og arterietrykket (16).

Det er antatt at morfin har en vasodilaterende effekt ved lungeødem $(3,17,31)$. Man har begrunnet dette $\mathrm{i}$ tre studier fra årene 1966-76, der utvalgene besto av henholdsvis 12 hunder, 12 pasienter med hjerteinfarkt (der ingen fikk morfin som eneste medikament) og 13 pasienter med mildt lungeødem $(18,19,33)$. I Vismara og medarbeideres studie (19) ble det imidlertid konkludert med at det må være en annen effekt enn den antatte vasodilatasjonen som er årsaken til at man har sett en klinisk bedring av lungeødem ved bruk av morfin - noe som ble støttet av flere studier frem mot 1990-årene $(20,21,34)$.

I 1994 viste et forsøk med blodårer fra hund in vitro at morfin har en relakserende effekt på den glatte muskulaturen i både vener og arterier (22) - en effekt som trolig er en følge av histaminfrigjøring $(23,35)$. I 2008 ble det i et amerikansk forsøk funnet en doseavhengig vasodilatasjon av morfin $i$ lungekretsløpet hos katter in vivo, uttrykt ved redusert arteriell karmotstand (36). Hvorvidt de fysiologiske effektene av morfin er de samme hos mennesker og i hvilken grad disse effektene har betydning på den endrede hemodynamikken ved lungeødem, er foreløpig lite kartlagt.

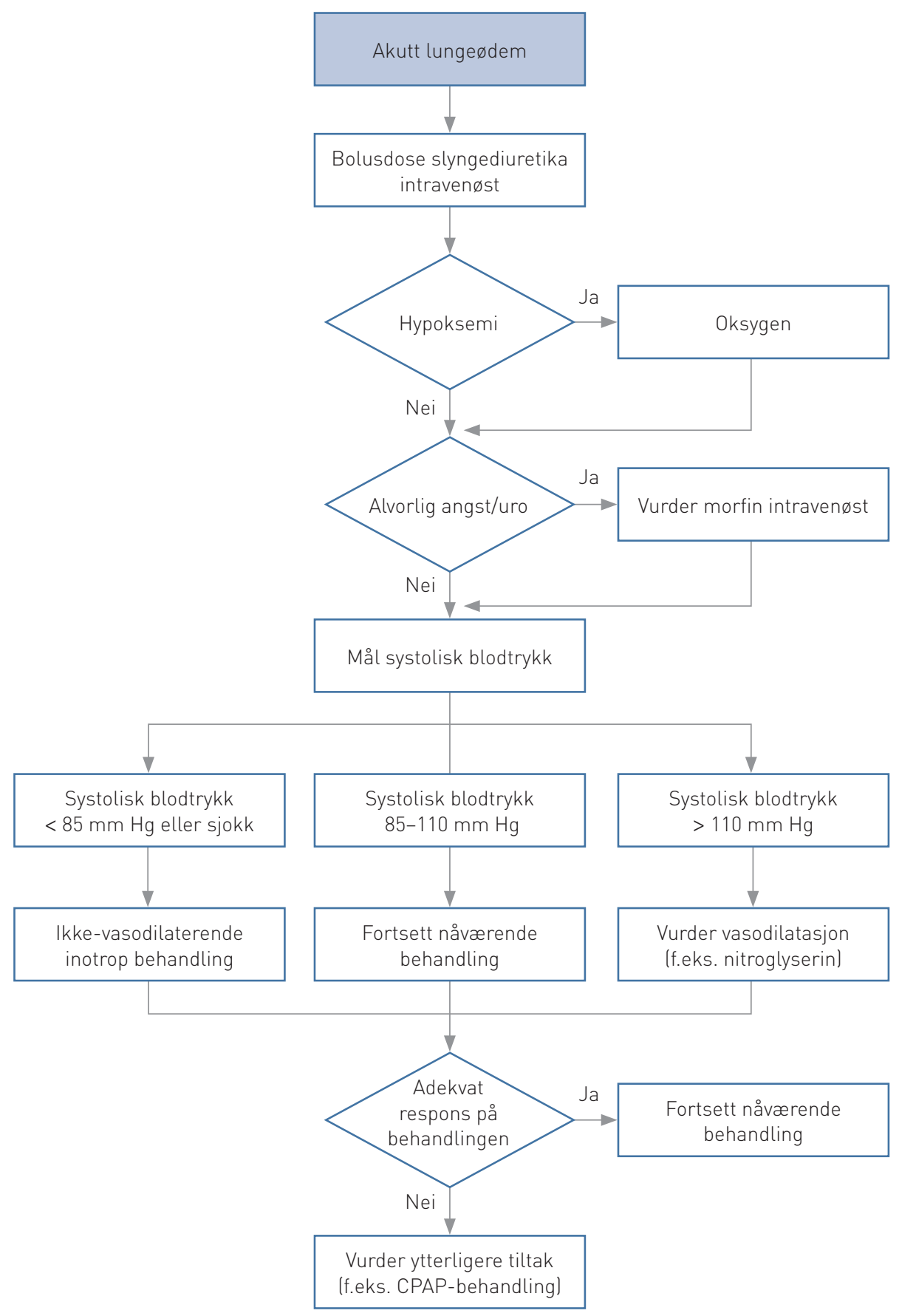

Figur 1 Algoritme for behandling av akutt lungeødem, ifølge retningslinjene fra European Society of Cardiology fra 2012, som anbefaler at 4-8 mg morfin intravenøst kan vurderes og eventuelt gjentas ved behov ved alvorlig angst eller uro (12)

Et forsøk fra 1979 med 28 pasienter som gjennomgikk koronar bypass-operasjon, viste at store doser morfin $(0,5 \mathrm{mg} / \mathrm{kg})$ ga en forbigående kraftig reduksjon av perifer karmotstand (37). De samme dosene ga også økt volumkapasitet på venesiden. Om disse funnene er representative for pasienter med lungeødem, er usikkert. I tillegg dreier dette seg om vesentlig større doser enn det man gir i dag.

For å oppsummere: Selv om det har vært beskrevet en viss dilatasjon av blodårene, er det sannsynligvis morfinets angstdempende effekt via redusert sympatikusaktivitet som har størst betydning ved lungeødem, uten at denne mekanismen er fullt klarlagt $(4,16,24)$.

\section{Uheldige fysiologiske effekter}

De vanligste bivirkningene av morfin er obstipasjon og kvalme. Mens obstipasjon ikke har betydning i akuttmedisinsk sammenheng, er det beskrevet at mellom en 
tredel og en femdel av pasientene opplever kvalme ved bruk av opioider $(38,39)$. Oppkast forekommer omtrent halvparten så hyppig som dette igjen. De europeiske retningslinjene anbefaler tillegg av $10 \mathrm{mg}$ metoklopramid for å motvirke kvalme dersom man gir morfin (12).

Kvalme ved lungeødem er en uheldig bivirkning både på grunn av det subjektive ubehaget og fordi kvalme utløser katekolaminfrigjøring som gjør at arterietrykket og dermed hjertets arbeid øker (25). Kvalme og eventuelt oppkast vil være svært uheldig dersom det er behov for behandling med kontinuerlig overtrykk (CPAP), noe European Society of Cardiology anbefaler å vurdere ved perifer oksygenmetning under $90 \%$ (12). Oppkast er kontraindikasjon for CPAP-behandling på grunn av risikoen for aspirasjon.

Det er funnet at morfin gir en depresjon av myokard som gir seg utslag i redusert hjertefrekvens og minuttvolum (40). Denne effekten kan være negativ for et kretsløp der hjertet allerede er i ferd med å svikte.

En fryktet bivirkning av morfin er respirasjonsdepresjon. Det skjer regelmessig fatale hendelser som følge av opioidindusert respirasjonsdepresjon, til tross for at nalokson er en effektiv antagonist. Opioider virker på respirasjonssenteret slik at både frekvensen og tidevolumet synker (41). Effekten ser ut til å være doseavhengig. Allerede ved lave doser blir respirasjonsmønsteret uregelmessig (42). I tillegg sløves både de perifere kjemoreseptorene (i aorta, carotis og lungevevet) og de sentrale (i medulla, atskilt fra selve respirasjonssenteret), slik at de blir mindre følsomme for økt $p \mathrm{CO}_{2}$ (41) og lav $\mathrm{pO}_{2}$ (42). En slik effekt på følsomheten for $p \mathrm{CO}_{2}$ ble registrert hos samtlige av de 66 friske deltakerne i en studie fra 2001 (39).

I en oversiktsartikkel fra 2010 er det likevel lav insidens av respirasjonsdepresjon som følge av opioidbehandling - den er kun $0,5 \%$ (43). Artikkelen er blant annet basert på en studie fra Sverige med 14000 postoperative pasienter der insidensen ble målt til $0,09 \%$ (44). Dette var riktignok etter morfin epiduralt (4 mg), slik at sammenlikningen har visse begrensninger. For postoperative pasienter i Storbritannia anslås insidensen til $1 \%(42)$.

\section{Heterogene prognoser}

I en oversiktsartikkel fra 2008 poengterer Sosnowski (11) at det ser ut til å være en sammenheng mellom bruk av morfin og forverring av pasientens tilstand, basert på fem studier fra 1987-2003 (10, 26-29). En av disse er en mindre studie om prehospital behandling av lungeødem. Den viste at $38 \%$ av pasientene som ble behandlet med morfin og furosemid, opplevde subjektiv forverring, mot ingen av pasientene som fikk nitroglyserin og furosemid (10). Disse fem studiene er riktignok preget av mindre gode vitenskapelige metoder og små utvalg, men resultatene kan antyde at det er en sammenheng mellom morfin og forverring samt at morfin blir gitt til de sykeste pasientene.

Den hittil største studien som omhandler morfin og lungeødem, ble publisert i 2008 av Peacock og medarbeidere (2). Dette er en retrospektiv analyse av et material fra det amerikanske ADHERE-registeret (Acute Decompensated Heart Failure National Registry) og omfatter i overkant av 147000 pasienter som ble innlagt for behandling av akutt dekompensert hjertesvikt. Disse ble fordelt på to kohorter ut fra om de fikk intravenøs morfin eller ikke. Nær 21000 fikk morfin. Etter å ha justert for årsaker som fra tidligere er kjent for å gi høy dødelighet $\mathrm{i}$ sykehus, deriblant høy alder, troponinstigning og hypertensjon, sto morfin igjen som en uavhengig faktor for økt dødelighet, med en oddsratio på 4,84 (95\% KI: 4,52-5,18; $\mathrm{p}<0,001)$. I tillegg ble det funnet signifikante sammenhenger mellom morfin og økt intubasjonsrate, flere intensivinnleggelser og lengre sykehusopphold.

I en tilsvarende, mindre studie fra 2003-07 i Storbritannia, der 541 pasienter fikk morfin ved lungeødem, fant man imidlertid ingen signifikant sammenheng mellom morfin og dødelighet (1). Man fant for øvrig heller ingen sammenheng mellom bruk av morfin og bedring av pustebesvær i form av pasientopplevd dyspné i løpet av den første timen.

I 2011 ble det gjort en retrospektiv studie i Israel med 2336 pasienter (30). De benyttet en liknende risikojustering som i studien basert på ADHERE-registeret, men i tillegg konstruerte de en kontrollgruppe som var så lik pasientgruppen som mulig (propensity score matching) som ikke fikk morfin. Etter dette var det ingen signifikant sammenheng mellom morfin og sykehusdødelighet. Både i den europeiske og den israelske studien var det en tendens til forverring ved morfinbehandling, men forskjellen ble ikke signifikant. Ikke i noen av studiene var det bedre prognoser ved bruk av morfin.

\section{Diskusjon}

Litteraturen omkring effekten av morfin i behandling av lungeødem er begrenset til observasjonsstudier samt noen få eldre randomiserte kliniske studier. Observasjonsstudiene vi har omtalt, antyder en sammenheng mellom morfin og dødelighet, mens ingen av studiene viser bedre prognoser ved bruk av morfin.

Ved vurdering av slike observasjonsstudier må man være oppmerksom på muligheten for effektforveksling - man ser på sammenhengen mellom morfin og uheldige utfall i retrospekt. Da er det vanskelig å avgjøre om de pasientene som kom inn med mer alvorlig hjertesvikt og som fikk morfin, hadde økt dødelighet som følge av morfinet eller som følge av at de hadde en mer alvorlig hjertesvikt i utgangspunktet. Resultatene i den israelske studien kan tyde på dette, da det i gruppen som fikk morfin var signifikant økt dødelighet, mens forskjellene etter justering (propensity score) ikke var signifikante. I en retrospektiv studie vil det heller ikke være synlig om intubasjon er en «bivirkning» av at pasienten fikk morfin eller om pasienten fikk morfin som sedativ i forbindelse med intubasjonen.

Slike ulemper ved disse studiene gjør at det ikke sikkert kan konkluderes om det er sammenheng mellom morfin og dødelighet, til tross for at man har forsøkt å justere for forskjeller i basaldata mellom gruppene. $\mathrm{Vi}$ kan derfor ikke fastslå hvorvidt bruken er risikofri.

Det ser ikke ut til å være holdepunkter for at alvorlig respirasjonsdepresjon er et utbredt problem ved bruk av morfin. Kvalme, derimot, er en langt vanligere bivirkning, noe samtidig bruk av antiemetika kan korrigere. Kvalme kan ses på som en ubehagelig, men ufarlig bivirkning, men den kan være alvorlig hvis pasienten samtidig får CPAP-behandling. Dette illustrerer hvordan morfin vil ha ulik nytte og risiko i forskjellige subpopulasjoner. Tilsvarende vil den kardiodepressive effekten som er beskrevet, kunne være svært ugunstig når den kardiale kapasiteten er svekket, mens den ikke vil være særlig avgjørende hos hypertensive pasienter.

Morfinbruken ved lungeødem har tradisjonelt vært begrunnet med morfinets effekt som vasodilatator og anxiolytikum $(3,12$, $16,17,31)$. Kunnskapsgrunnlaget for de vasodilaterende effektene på lungekretsløpet er imidlertid tynt, og det er ikke stadfestet hvilken betydning disse effektene faktisk har ved lungeødem. Morfinets fremste positive virkning på hemodynamikken ligger trolig $\mathrm{i}$ de angstdempende egenskapene. Nitroglyserin har langt større effekt på både fyllingstrykk og arterietrykk ved lungeødem, eventuelt i kombinasjon med furosemid (7), slik at morfinets eventuelle rolle som vasodilatator er mindre viktig. Dette gjenspeiles i retningslinjene fra European Society of Cardiology, som anbefaler morfin kun ved alvorlig angst eller uro (12).

Som et apropos til dette kan det nevnes at benzodiazepiner har vært foreslått som alternativ til morfin ved lungeødem $(4,25)$. Foreløpig har disse ingen anbefalt plass $\mathrm{i}$ behandlingen. Likevel er dette interessant fordi benzodiazepiner over lengre tid har vist gode egenskaper som anxiolytika, i tillegg til at de har gunstige karfysiologiske effekter (45). I en litteraturstudie anbefales 
benzodiazepiner i behandlingen av brystsmerter på grunn av disse egenskapene, og man fremholder flere forhold som taler for at de kunne være et alternativ også ved lungeødem (45).

\section{Konklusjon}

Morfin er fremdeles i bruk ved lungeødem, til tross for at det mangler sikker kunnskap om effekt. En randomisert, kontrollert studie er nødvendig for å avklare effekten, og særlig risikoen, ved bruk av morfin ved lungeødem. Fordi de gunstige effektene ikke er godt nok dokumentert, og fordi risikoen for økt dødelighet ikke kan utelukkes, kan det argumenteres for at man burde fraråde bruken.

\section{Christoffer Ellingsrud (f. 1985)}

er medisinstudent.

Forfatter har fylt ut ICMJE-skjemaet og oppgir ingen interessekonflikter.

\section{Stefan Agewall (f. 1960)}

er overlege og professor i kardiologi ved Universitetet i Oslo.

Forfatter har fylt ut ICMJE-skjemaet og oppgir ingen interessekonflikter.

\section{Litteratur}

1. Gray A, Goodacre S, Seah M et al. Diuretic, opiate and nitrate use in severe acidotic acute cardiogenic pulmonary oedema: analysis from the $3 \mathrm{CPO}$ trial. QJM 2010; 103: 573-81.

2. Peacock WF, Hollander JE, Diercks DB et al. Morphine and outcomes in acute decompensated heart failure: an ADHERE analysis. Emerg Med J 2008; 25: 205-9.

3. Nieminen MS, Böhm M, Cowie MR et al. Executive summary of the guidelines on the diagnosis and treatment of acute heart failure: the Task Force on Acute Heart Failure of the European Society of Cardiology. Eur Heart J 2005; 26: 384-416.

4. Mattu A, Martinez JP, Kelly BS. Modern management of cardiogenic pulmonary edema. Emerg Med Clin North Am 2005: 23: 1105-25.

5. Grayson S, Gandy WE. CHF treatment: is furosemide on the way out? Rethinking the pulmonary edema cocktail. EMS World 2012; 41: 20-4.

6. Coons JC, McGraw M, Murali S. Pharmacotherapy for acute heart failure syndromes. Am J Health Syst Pharm 2011; 68: 21-35

7. Cotter G, Metzkor E, Kaluski E et al. Randomised rial of high-dose isosorbide dinitrate plus lowdose furosemide versus high-dose furosemide plus low-dose isosorbide dinitrate in severe pulmonary oedema. Lancet 1998; 351: 389-93.

8. Hall M, Griffiths R, Appadu B. Is morphine indicated in acute pulmonary oedema. Emerg Med J 2005: 22: 391.

9. Cattermole GN, Graham CA. Opiates should be avoided in acute decompensated heart failure. Emerg Med J 2009; 26: 230-1.

10. Hoffman JR, Reynolds S. Comparison of nitroglycerin, morphine and furosemide in treatment of presumed pre-hospital pulmonary edema. Chest 1987; 92: 586-93.

11. Sosnowski MA. Review article: lack of effect of opiates in the treatment of acute cardiogenic pulmonary oedema. Emerg Med Australas 2008; 20 384-90.

12. McMurray JJ, Adamopoulos S, Anker SD et al.
ESC guidelines for the diagnosis and treatment of acute and chronic heart failure 2012: The Task Force for the Diagnosis and Treatment of Acute and Chronic Heart Failure 2012 of the European Society of Cardiology. Developed in collaboration with the Heart Failure Association (HFA) of the ESC. Eur J Heart Fail 2012; 14: 803-69.

13. Andersen G, Eritsland J, Mangschau A. Metodebok for indremedisinere. Akutt hjertesvikt - lungeødem. Oslo: Oslo universitetssykehus, 2012. www.helsebiblioteket.no/retningslinjer/ metodebok/hjerte-kar-sykdommer/ akutt-hjertesvikt-lungeødem (25.2.2014).

14. Norsk legemiddelhåndbok. T.8.6.2 Lungeødem Oslo: Norsk legemiddelhåndbok, 2013. http://legemiddelhandboka.no/Terapi/12649 (25.2.2014)

15. Johnson MR. Acute Pulmonary Edema. Curr Treat Options Cardiovasc Med 1999; 1: 269-76.

16. Hodt A, Steine K, Atar D. Medikamentell og ventilatorisk behandling ved akutt hjertesvikt. Tidsskr Nor Lægeforen 2006: 126: 749-52.

17. Allison RC. Initial treatment of pulmonary edema: a physiological approach. Am J Med Sci 1991; 302 385-91.

18. Vasko JS, Henney RP, Oldham HN et al. Mechanisms of action of morphine in the treatment of experimental pulmonary edema. Am J Cardiol $1966 ; 18: 876-83$

19. Vismara LA, Leaman DM, Zelis $R$. The effects of morphine on venous tone in patients with acute pulmonary edema. Circulation 1976; 54: $335-7$.

20. Timmis AD, Rothman MT, Henderson MA et al. Haemodynamic effects of intravenous morphine in patients with acute myocardial infarction complicated by severe left ventricular failure. BMJ 1980; 280: 980-2

21. Redmond AD. The haemodynamic effects of morphine. Arch Emerg Med 1987; 4: 131-2

22. Greenberg S, McGowan C, Xie J et al. Selective pulmonary and venous smooth muscle relaxation by furosemide: a comparison with morphine. J Pharmacol Exp Ther 1994: 270: 1077-85.

23. Grossmann M, Abiose A, Tangphao 0 et al. Morphine-induced venodilation in humans. Clin Pharmacol Ther 1996; 60: 554-60.

24. Kosowsky J, Abraham WT, Storrow A. Evaluation and management of acutely decompensated chronic heart failure in the emergency department. Congest Heart Fail 2001; 7: 124-36

25. Bosomworth J. Rural treatment of acute cardiogenic pulmonary edema: applying the evidence to achieve success with failure. Can J Rural Med 2008; 13: 121-8.

26. Chambers JA, Baggoley CJ. Pulmonary oedema prehospital treatment. Caution with morphine dosage. Med J Aust 1992; 157: 326-8.

27. Beltrame JF, Zeitz CJ, Unger SA et al. Nitrate therapy is an alternative to furosemide/morphine therapy in the management of acute cardiogenic pulmonary edema. J Card Fail 1998; 4: 271 -9.

28. Sacchetti A, Ramoska E, Moakes ME et al. Effect of ED management on ICU use in acute pulmonary edema. Am J Emerg Med 1999; 17: $571-4$

29. Fiutowski M, Waszyrowski T, Krzemińska-Pakuła $M$ et al. Clinical presentation and pharmacologica therapy in patients with cardiogenic pulmonary oedema. Kardiol Pol 2004; 61: 561-9, discussion 570.

30. lakobishvili Z, Cohen E, Garty M et al. Use of intravenous morphine for acute decompensated hear failure in patients with and without acute coronary syndromes. Acute Card Care 2011; 13: 76-80.

31. Heart Failure Society of America. Evaluation and management of patients with acute decompensated heart failure. St. Paul, MN: HFSA, 2010. www.sciencedirect.com/science/article/pii/ S1071916410002277 (14.2.2014).

32. Yancy CW, Jessup M, Bozkurt B et al. 2013 ACCF/ AHA guideline for the management of heart failure: a report of the American College of Cardiology Foundation/American Heart Association Task Force on practice guidelines. Circulation 2013; 128: e240-327

33. Lee G. DeMaria AN, Amsterdam EA et al. Compa- rative effects of morphine, meperidine and pentazocine on cardiocirculatory dynamics in patients with acute myocardial infarction. Am J Med 1976 ; 60: $949-55$

34. Zelis R, Mansour EJ, Capone RJ et al. The cardiovascular effects of morphine. The peripheral capacitance and resistance vessels in human subjects. $\mathrm{J}$ Clin Invest 1974; 54: 1247-58.

35. Rosow CE, Moss J, Philbin DM et al. Histamine release during morphine and fentanyl anesthesia. Anesthesiology 1982; 56: 93-6.

36. Kaye AD, Hoover JM, Kaye AJ et al. Morphine, opioids, and the feline pulmonary vascular bed Acta Anaesthesiol Scand 2008; 52: $931-7$

37. Hsu HO, Hickey RF, Forbes AR. Morphine decreases peripheral vascular resistance and increases capacitance in man. Anesthesiology 1979; 50 98-102.

38. Smith HS, Laufer A. Opioid induced nausea and vomiting. Eur J Pharmacol 2014: 722: 67-78.

39. Cepeda MS, Farrar JT, Roa JH et al. Ethnicity influences morphine pharmacokinetics and pharmacodynamics. Clin Pharmacol Ther 2001; 70: 351-61.

40. Riggs TR, Yano Y, Vargish T. Morphine depression of myocardial function. Circ Shock 1986; 19: 31-8.

41. Radke JB, Owen KP, Sutter ME et al. The effects of opioids on the lung. Clin Rev Allergy Immunol 2014; 46: 54-64.

42. Pattinson KT. Opioids and the control of respiration. Br J Anaesth 2008; 100: 747-58.

43. Dahan A, Aarts L, Smith TW. Incidence, Reversal, and Prevention of Opioid-induced Respiratory Depression. Anesthesiology 2010; 112: 226-38

44. Rawal N, Arnér S, Gustafsson LL et al. Present state of extradural and intrathecal opioid analgesia in Sweden. A nationwide follow-up survey. Br J Anaesth 1987; 59: 791-9

45. Huffman JC, Stern TA. The use of benzodiazepines in the treatment of chest pain: a review of the literature. J Emerg Med 2003; 25: 427-37.

Mottatt 17.3. 2014, første revisjon innsendt 7.8. 2014, godkjent 29.10. 2014. Redaktør: Are Brean. 